MATEC Web of Conferences 45, 01002 (2016)

DOI: $10.1051 /$ matecconf $/ 20164501002$

(C) Owned by the authors, published by EDP Sciences, 2016

\title{
Investigation of Microstructure in Solid State Welded Al-Cu-Li alloy
}

\author{
Kookil No ${ }^{1}$, Ye Rim Lee ${ }^{1+}$, Kyung-Ju Min ${ }^{2}$ and Ho-Sung Lee ${ }^{1,2}$ \\ ${ }^{1}$ University of Science \& Technology, Republic of Korea \\ +currently at Korea Institute of Materials Science, Republic of Korea \\ ${ }^{2}$ Korea Aerospace Research Institute, Republic of Korea
}

\begin{abstract}
Al-Li alloys have been extensively used in aerospace vehicle structure since the presence of lithium increases the modulus and reduce the density of the alloy. Especially the third generation Al-Cu-Li alloy shows enhanced fracture toughness at cryogenic temperatures so that the alloy has been used on the fuel tank of space launchers, like Super Lightweight External Tank of the Space Shuttle. Since the commercial size of the plate cannot accommodate the large tank size of the launcher, joining several pieces is required. However, lithium is highly reactive and its compounds can decompose with heat from conventional fusion welding and form different types of gases which result in formation of defects. In this study, the microstructure change is investigated after solid state welding process to join the $\mathrm{Al}-\mathrm{Cu}-\mathrm{Li}$ sheets with optical and transmission electron microscopic analysis of precipitates.
\end{abstract}

\section{Introduction}

Aluminum lithium alloy has been used for aerospace structure because its higher modulus and lower density comparing to conventional aerospace aluminum alloy [1]. The alloy also shows superior mechanical properties in higher specific strength, enhanced resistance to high cycle fatigue, and high fracture toughness at cryogenic temperatures [2]. One of the well-known application of aluminum lithium alloys is for space launch vehicle. By using aluminum lithium alloy and friction stir welding to super lightweight external tank for space shuttle, total dry weight is reduced by about $11 \%[3,4]$. It is known that fusion welding of Al-Li alloys is difficult due to the reactive property of element $\mathrm{Li}$ during melting and causes porosity, cracking and low joint efficiency $[5,6]$. Solid state welding generally involves heating the metal with a suitable amount of pressure so that homogeneous and complete microstructural joining is possible with no melting of the parts to be joined. It means the process offers advantages over fusion welding which exhibit solidification problems (e.g. porosity, hot cracking, segregation etc).

Solid state diffusion welding is an attractive manufacturing method for aerospace applications where mechanical properties in the bond area and a sound metallurgical bond are important [7]. Diffusion welding is such a process in which two matched surfaces are held together at a temperature range between 0.5 of the absolute melting temperature of the materials and the room temperature under a low pressure without causing a macroscopic plastic deformation in the materials.. Diffusion welding consisted of initial creep, which is followed by vacancy diffusion to allow for complete void closure and homogeneous welding at the interface [8]. This process of void closure is the opposite to the cavity nucleation process of the final stage of creep rupture. Cavitation model for nucleation and growth of cavity requires the critical size of stable cavity based on surface energy and applied stress [9]. Therefore, thermodynamically there is a critical size of void for enclosing and complete welding. The whole mechanism is governed by surface diffusion, volume diffusion, grain boundary diffusion, and power-law creep. The welding is formed from atomic migration across an interface in a solid state, and there is no metallurgical discontinuity at the interface and hence mechanical properties and microstructure at the bonded region are not different from those of the base metal. This is different from a brazing process in which a foreign metal with a lower melting point is used to weld together.

In friction welding, rotating welding tool generates frictional heat and causes material at the interface to deform and with a profiled pin is plunged into the joining areas between two pieces of plate material [10]. By keeping the tool rotating and moving it along the seam to be joined, heat from friction between the welding tool and the workpiece causes the plate to soften without melting. The softened material is transferred to the trailing edge of the tool pin as the tool travels along the weld line. The workpiece is forged by the intimate contact of the tool shoulder and the pin profile. After cooling, a solid phase bond is created between the pieces of metal that have been stirred and mixed together. This process requires low energy input and joins materials 
without filler metals or shielding gas. In addition, in most cases the localized heat during friction welding results in a refined microstructure, which can provide improved strength relative to the parent material.

The present work is to investigate the microstructure change including phase and microstructure evolution of diffusion welded and friction stir welded Al-Cu-Li alloy. Microstructures present formation and evolution in representative precipitates including $\theta\left(\mathrm{Al}_{2} \mathrm{Cu}\right), \delta\left(\mathrm{Al}_{3} \mathrm{Zr}\right)$, and $\mathrm{T}\left(\mathrm{Al}_{\mathrm{x}} \mathrm{Li}_{\mathrm{y}} \mathrm{Cu}\right)$ series.

\section{Experimental}

The Al-Li alloy was obtained from Constellium Global Aerospace, France. The contents of the alloy was examined by inductively coupled plasma optical emission spectrometer (ICP-OES, 720, Agilent, CA, USA).

Table 1. Composition of the Al-Li alloy (wt/o)

\begin{tabular}{|c|c|c|c|c|c|c|}
\hline $\mathbf{A g}$ & $\mathbf{A l}$ & $\mathbf{C r}$ & $\mathbf{C u}$ & $\mathbf{F e}$ & $\mathbf{L i}$ & $\mathbf{M g}$ \\
\hline $\mathbf{0 . 1 9}$ & 94.56 & 0.0004 & 3.76 & 0.05 & 1.00 & 0.28 \\
\hline $\mathbf{M n}$ & $\mathbf{N i}$ & $\mathbf{P b}$ & $\mathbf{S i}$ & $\mathbf{T i}$ & $\mathbf{Z n}$ & $\mathbf{Z r}$ \\
\hline $\mathbf{0 . 0 2}$ & 0.0015 & 0.0003 & 0.02 & 0.01 & 0.001 & 0.11 \\
\hline
\end{tabular}

For diffusion welding, two sheets in thickness of $5 \mathrm{~mm}$ were prepared and the surface of sheets was carefully prepared by special procedure [4] since the surface condition was vitally important for complete bonding. The surfaces to be bonded were machined and grinded with 600 grit sand paper before chemical cleaning. Ultrasonic rinsing in a high-purity solvent, and in distilled water followed. The rinsed surfaces were then air dried with clean filtered air. Prior to diffusion welding, the specimens were immediately cleaned again with a high-purity solvent and dried. Then, two sheets are sequentially stacked in the tool according to the present embodiment. After stacking, the tool is sealed and vacuumed and then, the tool is heated to $500{ }^{\circ} \mathrm{C}$. Hydrostatic gas pressure of 50MPa is applied for 1,2 , and 3 hours. Solid state welding system is shown in Figure 1

Two plates were butt-joined by friction stir welding and the welding direction was parallel to rolling direction with coupons of $300 \mathrm{~mm}$ in length and $100 \mathrm{~mm}$ in width. One plate where the direction of rotation is the same as that of welding is called the advancing side (AS), with the other plate designated as being the retreating side (RS). The range of welding parameter is $600 \mathrm{RPM}$ for rotation speed and $300 \mathrm{~mm} / \mathrm{min}$ for travel speed. After welding, all of the specimens were inspected by x-ray radiography and one with defects are discarded. For optical microstructure, the specimens were etched with Graff-Sargent solution followed by Keller's solution [11]. The etched surfaces were observed by optical microscopy (Metallux 3, Leica Microsystems). The details were examined by transmission electron diffraction microscopy (TEM; Titan G2 Double Cs corrected TEM, Philips/FEI) with an acceleration voltage of $200 \sim 300 \mathrm{kV}$, and composition was determined by energy-dispersive spectroscopy (EDS), electron energy loss spectroscopy (EELS) and scanning TEM-high angle annular dark field
(STEM-HAADF) in the TEM. Samples for the TEM observation were prepared on Molybdenum-grid by a focused ion beam (FIB)-SEM hybrid system equipped with a $\mathrm{Ga}+$ focused ion beam (FIB) column (FIB; SMI3050SE, SII Nanotechnology Inc.)

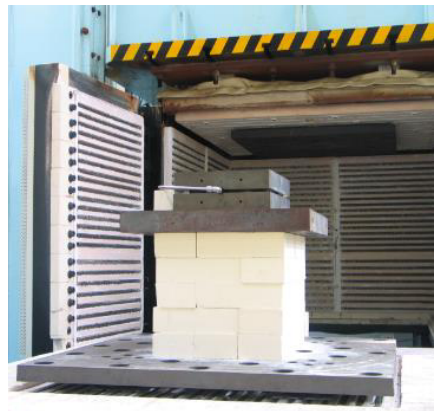

(a)

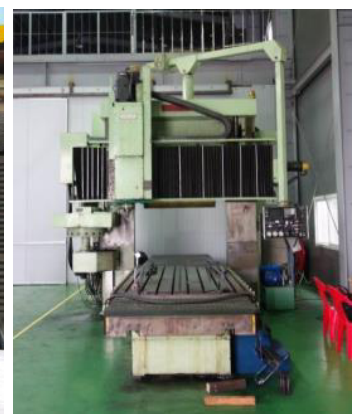

(b)
Figure 1. Photographs of solid state joining apparatus: (a) diffusion bonding press (b) friction stir welding machine

\section{Results and Discussion}

Figure 2 shows metallographic microstructure with identification of some of precipitates. Precipitates are found at the grain boundaries, as shown in Figure 2(b). The precipitates are easy to nucleate at the gain boundaries because the high dislocation density is suitable for the diffusion of the solute elements at the grain boundaries. The precipitates such as $\theta^{\prime}, \alpha$, and $\delta$ ' phases, formed at relatively low temperature, are known as a spherical shape. Furthermore, as $\theta$ phase is grown from GP zone, $\theta$ ' ' and $\theta$ ' phases, the size of the $\theta$ series is varied from $10 \mathrm{~nm}$ to $5 \mu \mathrm{m}$. In contrast, the hightemperature precipitates including $\mathrm{T}_{1}$ and $\mathrm{T}_{2}$ are reported as a pin- and platelet-like shape. It is known that $T_{1}$ phase has a plate-shaped morphology and is the primary phase responsible for the strengthening effect in this alloy [12]. The nucleation of this phase is based on the presence of secondary alloying elements such as $\mathrm{Mg}$ and $\mathrm{Ag}$ and $\mathrm{T} 1$ phase usually coexists with the $\theta^{\prime}\left(\mathrm{Al}_{2} \mathrm{Cu}\right)$ phase. $\mathrm{Zr}$ contributes to form coherent spherical $\beta^{\prime}\left(\mathrm{Al}_{3} \mathrm{Zr}\right)$ precipitates which are very stable at high temperatures.

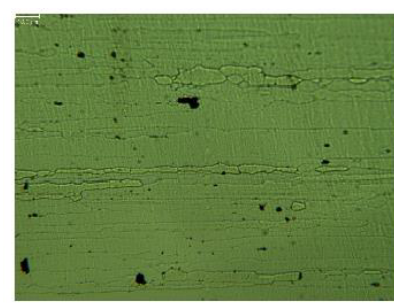

(a)

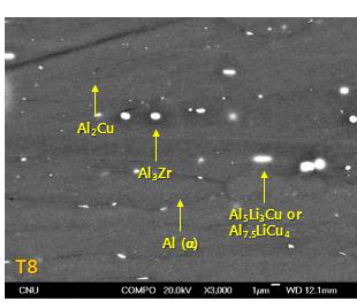

(b)
Figure 2. (a) Optical microscopy structure and (b) TEM photograph with phase identification 

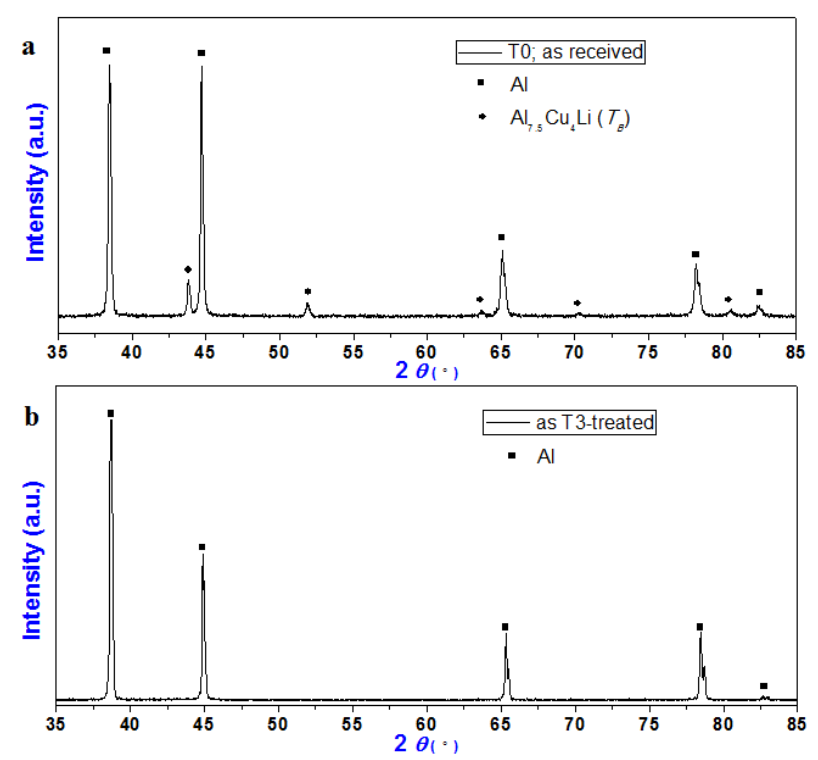

Figure 3. XRD pattern of this alloy

Figure 3 reveals XRD patterns of AA2195 samples processed by different. The pattern of AA2195-T0 in Figure 3(a) reveals two phases such as $\mathrm{Al}$ and $\mathrm{Al}_{7.5} \mathrm{Cu}_{4} \mathrm{Li}$. The phase of $\mathrm{Al}_{7.5} \mathrm{Cu}_{4} \mathrm{Li}$ was produced by a natural aging process. Changes in the phases were detected after T3 solution treatment. As shown in Figure 3(b), AA2195-T3 reveals only $\mathrm{Al}$ peaks. This result indicated that all contents in AA2195-T0 were successfully solutiontreated and supersaturated into the $\mathrm{Al}$ phase. Thus, the peaks for the $\mathrm{Al}$ phase were shifted to higher angle compared to ICDD (International Center for Diffraction Data) [13]. This shift indicates that the $\mathrm{Al}$ atoms were substituted by other atoms like $\mathrm{Mg}, \mathrm{Ag}$ and $\mathrm{Cu}$. Furthermore, the Al lattice was shrunken and distorted by the atoms replaced.

The microstructure of diffusion welded interface is shown in Figure 4. After 2 hours of bonding, the interface is still clearly visible, but the grain growth after recrystallization is apparent for the longer time as shown in Figure 4(c). Therefore, it was difficult to obtain an appropriate welding condition at this temperature. It is recommended that the diffusion welding temperature would be lower or welding time shorter for this alloy.

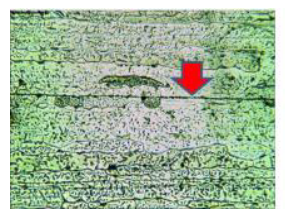

(a)

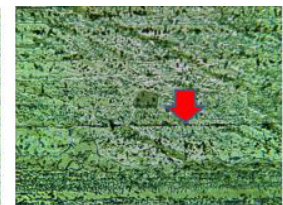

(b)

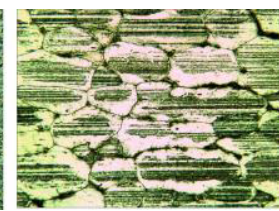

(c)
Figure 4. Micrographs (X200) of diffusion welded interface welded for (1) one hour, (2) two hours, and (3) 3 hours under $50 \mathrm{MPa}$ at $500^{\circ} \mathrm{C}$

The cross sectional view of friction stir welded joint is shown in Figure 5 with an example of onion rings, which is the prominent feature during the FSW. The distinguished lines in Figure 5 is called onion rings. In this region, it shows that the materials are well mixed along with rotating threaded pin. The rotating tool produce frictional heat and extrude a cylindrical shaped material around to the retreating side of the joint. Therefore, the formation of onion rings was caused by the rotation and advancing effects.

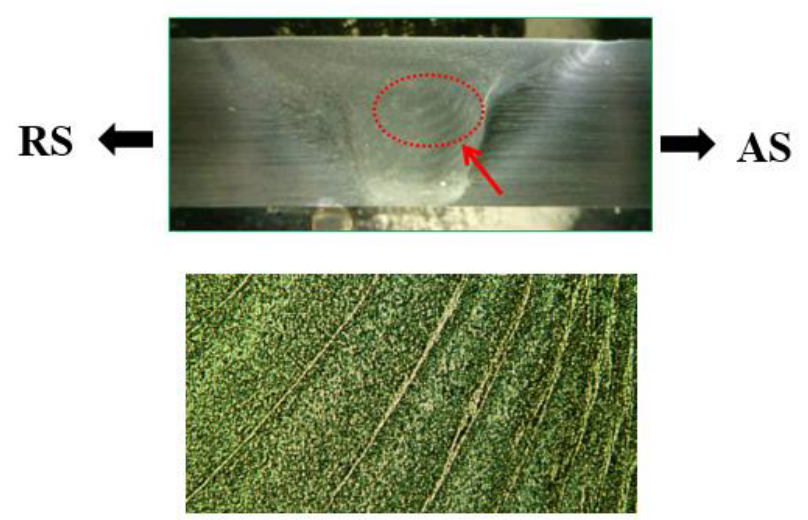

Figure 5. Cross sectional view of friction stir welded joint and a micrograph of onion rings
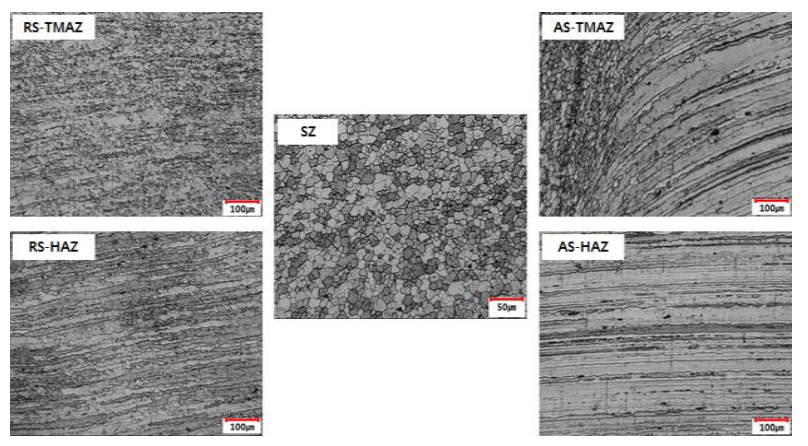

Figure 6. Microstructure of friction stir welded AA2195 at $600 \mathrm{rpm}-360 \mathrm{~mm} / \mathrm{min}$ condition [14]

The grain structure of friction stir welded joint is shown in Figure 6 and five distinct regions are stir zone (SZ), heat-affected zone (HAZ) and thermo-mechanical affected zone (TMAZ), which are obviously distinguished by their grain characteristics and distribution of precipitates for retreating side and advancing side. Stir zone (SZ) is the region, which has experienced temperatures and deformation to become fully recrystallized. This area had immediate interaction with the pin tool. Thermomechanically affected zone (TMAZ) is the region that has experienced plastic deformation in addition to heat from the process. This area has not undergone recrystallization and grains are deformed, elongated and rotated due to the strain to which they were subjected. Heat affected zone (HAZ) is the region without deformation, but has experienced only temperature increase during welding affecting the microstructure and/or mechanical properties. The microstructure is similar to that of parent metal and the grains are slightly overgrown as a result of the exposure to welding heat. The material located at the advancing side is mainly influenced by the friction from shoulder 
and pin, while at the retreating side, the dominating effects are extrusion and backfill from the advancing side and the shoulder. Figure 6 (AS-TMAZ) has shown the boundary between TMAZ and nugget in the advancing side and dynamic recrystallization has taken placed in this region.

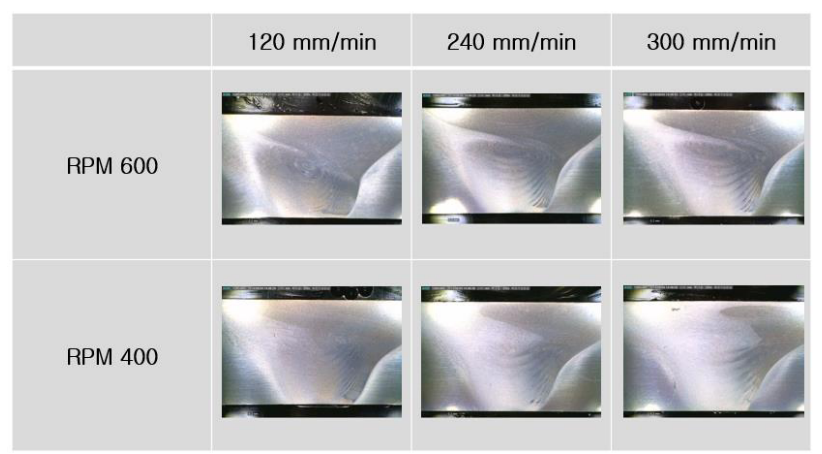

Figure 7. Macrostructure of friction stir welded joints

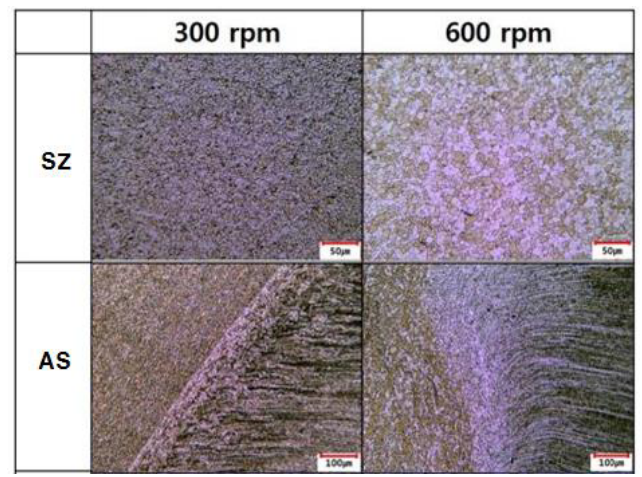

Figure 8. Effect of rotating speed on microstructure welded at $120 \mathrm{~mm} / \mathrm{min}$

Figure 7 shows typical macrostructure of friction stir welded joints at different process parameters. In macrostructure, it is hard to notice any distinguishable change on microstructure except at higher traveling speed, the orange ring marks become clearly visual. Effect of rotating speed is shown in Figure 8 for the specimen welded at $120 \mathrm{~mm} / \mathrm{min}$. At higher rotating speed, the distinction between HAZ and TMAX becomes disappear and this is due to the temperature increase at this region.

The grain size at high rotating speed (600RPM) is larger than that at 300RPM due to the heat generated by the plastic deformation.

Material in the stirred zone experience sufficient deformation and heat input which cause the complete dynamic recrystallization. However in case of insufficient or excessive rotational speed combined with too low downward force, wormhole defect was created as shown in Figure 9. Some of other weld defects observed in this study is summarized in Figure 10. The wormhole or tunnel defect is a kind of volumetric defect that may be discrete or continuous. Tunnel defects may occur at high or low tool advance per tool revolution. Defect location is dependent on the alloy and the welding parameters but is normally on the advancing side of the weld [15]. The occurrence of wormhole defects is more difficult to control in materials with high strength and low thermal conductivity. It is known that aluminum alloys are particularly prone to crown-side overheating defect due to local melting with production of brittle solidification products. The defect is not necessarily detectable by conventional non destructuve inspection. Recent development of automated phased array ultrasonics is known to be effective and under implementation [16].

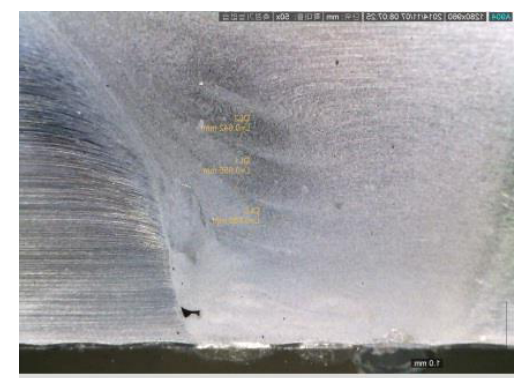

Figure 9. Detection of wormhole defect of friction stir welded at $400 \mathrm{rpm}-360 \mathrm{~mm} / \mathrm{min}$ condition

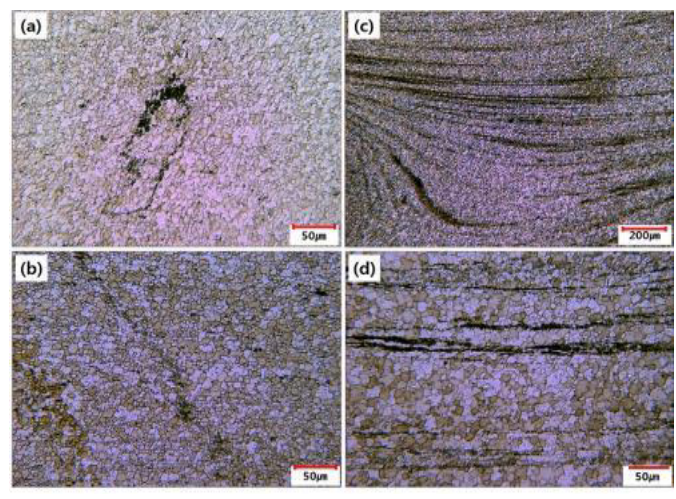

Figure 10. Examples of various weld defects : (a), (b)void (c) oxides alignment (d) cross direction voids

\section{Conclusion}

In this work, two different types of solid state welding methods are performed to join $\mathrm{Al}-\mathrm{Cu}-\mathrm{Li}$ alloy sheets. An attempt to diffusion welding results in grain growth after complete welding so that it needs further study to obtain optimum welding condition. For friction stir welding, a very good microstructural quality has been achieved and will be validated with mechanical testing.

\section{References}

1. A. R. C. Westwood, Material Science Technology, 6, 958-961 (1990).

2. R. J. H. Wanhill, Internal Journal of Fatigue, 16 3-20 (1994).

3. G. Adams, P. Pareti, J. Thompson, and K. Lawless, AEROMAT 2001, June 11-14, 2001, Los Ang3les, CA., U.S.A.

4. Information on http://www.nasa.gov/pdf/3752main ET Overview_Wanda_print.pdf

5. NASA FS-2005-04-025-MSFC, April 2005. 
6. J. H. Vickers, J. Fikes, J. R. Jackson, T. F. Johnson, J. K. Sutter, and R. A. Martin, "NASA Composite Cryotank Technology Demonstration: Overview", SAMPE 2012 Conference, Baltimore, MD, 2012.

7. H. S. Lee, in : Welding and Joining of Aerospace Materials, edited by M.C. Chaturvedi, Woodhead Publishing, Philadelphia, PA, USA (2012), Ch. 10 320-344

8. B. P. Kashyap and A. K. Mukherjee: Res. Mechanica, 17 (1986), pp. 293-355

9. A. H. Chokshi, A. K. Mukherjee, and T.G. Langdon: Mater. Sci. Eng., Vol. RI0(1993), pp. 237-74.

10. R. S. Mishra, Scripta Materialia, 58 pp. 325-326 (2008)

11. Standard Guide for Preparation of Metal Surfaces for Adhesive Bonding, ASTM D 2651-01, 2001.

12. P.S. Chen and B.N. Bhat, NASA/TM 211548, Alabama, 2002.

13. Powder Diffraction File, International Center for Diffraction Data, Newtown, PA. U.S.A.

14. Y. R. Lee, Effect of process parameters on friction stir welds of AA2195, M.S. Thesis, August 2015, University of Science \& Technology at Korea.

15. R. S. Mishra, U.S. patent $(6,923,362)$ on "Integral channels in metal components and fabrication thereof," August 2, 2005.

16. https://www.niar.wichita.edu/niarworkshops/Portals/ 0/WSU_Burford.pdf 